\title{
EDITORIAL
}

\section{New opportunities for respiratory research in Europe: FP7}

\author{
W. MacNee*, G. Viegi ${ }^{\#}$ and N. Kamel ${ }^{\ddagger}$
}

$\mathbf{T}$ he mission of the European Respiratory Society (ERS) is to promote respiratory health in Europe in order to alleviate suffering from respiratory disease. This is accomplished by promoting basic epidemiological and clinical respiratory research, collecting and disseminating scientific information, organising congresses and conferences, producing scientific publications, supporting training and continuous education in respiratory medicine, and collaborating with organisations that represent patients.

However, to successfully reach its mission the ERS also needs to focus on developing a sustainable advocacy strategy, directed at national and European policy and decision makers who set the political agenda, be it in education, research or public health. Policy interventions are a necessity if the growing trend of suffering and death from respiratory diseases is to be reversed. Therefore, the ERS launched a campaign at European Union (EU) level to inform decision makers about these diseases, as well as to gain their support and the commitment required to drive through change at policy level.

\section{PROMOTING LUNG HEALTH POLICY AT EU LEVEL}

Respiratory diseases have a huge impact across Europe for patients and in the utilisation of healthcare resources in terms of medication, hospital admissions, lost working days and anticipated mortality. The European Lung White Book [1], published by the ERS and the European Lung Foundation (ELF), represents the first comprehensive survey to raise public awareness and inform decision makers on the burden to society caused by lung diseases, including epidemiological data, but also environmental risk factors and the socioeconomic costs.

On a global level, the World Health Organization (WHO) has included chronic respiratory disorders as one of the main chronic diseases causing death in the 2005 global report "Preventing chronic diseases: a vital investment" [2]. Moreover, the WHO recently called for extra efforts in prevention, early diagnosis and treatment of such diseases, which could save 36 million lives worldwide by 2015 [2-4]. Therefore, there is an urgent need for respiratory diseases to be dealt with as a public-health issue.

*ERS President Centre of Inflammatory Research, Queens Medical Research Institute, Edinburgh, UK. " ERS Past President CNR Institute of Clinical Physiology, Pisa, Italy. "EU Office, European Respiratory Society, Brussels, Belgium.

STATEMENT OF INTEREST: None declared.

CORRESPONDENCE: N. Kamel, European Respiratory Society, 39-41 Rue d'Arlon, BE-1000 Brussels, Belgium. Fax: 32 22385361. E-mail: nadia.kamel@ersnet.org
In the present issue of the European Respiratory Journal, BOUSQUET et al. [5] highlight the novel Global Alliance against Chronic Respiratory Diseases (GARD). The objectives of GARD are three-fold: 1) to obtain all relevant data on chronic respiratory diseases worldwide; 2) to implement health promotion and prevention strategies; and 3) to develop strategies for the management of chronic respiratory diseases. The major breakthrough is that this will now be a global stepwise effort, both in high-, middle- and low-income countries. This will all be coordinated by the GARD secretariat at the WHO headquarters in Geneva, Switzerland [6].

How about Europe? There are three ERS specific activities at EU level which are needed, as follows.

\section{Preventive actions}

To work towards more stringent indoor and outdoor airquality levels and, in particular, a total ban on smoking in public places, as well as encouraging individual smokingcessation programmes.

\section{Environmental actions}

More research is needed into how environmental factors produce adverse health effects. This is needed to inform environmental policy.

The European Lung White Book [1] has shown how difficult it is to develop a pan-European approach to collecting and assessing data on the environmental effects on health. There is a need to close the knowledge gaps in data, which are often of insufficient quality with lack of comparability between countries.

\section{Science and research actions}

Although the link between the environment and health has been clearly proven, it is impossible to completely avoid exposure to tobacco smoke, pollen, car emissions etc., with the noticeable exception of tobacco smoke in countries where there is a smoking ban in indoor environments. Moreover, respiratory health not only depends on environmental exposure but numerous other factors, such as economic, social, nutritional and genetic, as well as the coexistence of other diseases.

Translational research into respiratory medicine must be made a high priority, since the legacy of respiratory diseases will remain for many years to come. Respiratory diseases need to be recognised as important and be placed in the same league of serious diseases such as cancer and cardiovascular disease. Accordingly, they need to be given a much greater priority 
(and visibility) in the relevant themes of the Community Research Framework programme, the main EU funding tool for research and development.

Due to the high costs of medication, the Community Research Framework programmes should especially encourage research into nonpharmacological approaches for respiratory diseases. In this respect, community funding is ever more relevant and necessary.

\section{RAISING THE VISIBILITY OF RESPIRATORY DISEASES IN FP7}

The launch of the European Lung White Book [1] at the European Parliament in November 2003 was a first-key attempt to attract the attention of policy makers to lung diseases and respiratory patients. ELF is the public voice of the ERS and forms an important element in this context as the objective of ELF is to link up the ERS output and make it available to the public. The core activity of ELF is to make expert medical information from lung specialists available, understandable, accurate and unbiased for the public. These may include individuals who suffer from respiratory diseases, as well as policy and decision makers.

Since 2004, the ERS has continued its activities to raise the visibility of respiratory diseases within the Health theme of the Seventh Framework Programme (2007-2013) of the European Community for research, technological development and demonstration activities (or simply FP7) [7]. FP7 is the main EU financial tool to support research and technological development in all scientific disciplines. After nearly 2 yrs of negotiations the political procedure has reached completion. Community funding for the next 7 yrs between 2007 and 2013 will total $€ 50.5$ billion. In 2005, the ERS met with key individuals in the European Commission, including the Research Commissioner J. Potočnik, to emphasise the need for an integrated pan-European research strategy for respiratory diseases in FP7.

At member-state level the ERS and the Forum of European Respiratory Societies sought additional support from national health and research ministries, to advocate for the inclusion of respiratory diseases in FP7. Since the European Parliament (EP) has a central role in the decision-making process, the ERS contacted key Members of the EP (MEP) to gather further support. Meetings were held directly between ERS officers and MEP keen to support the action to include respiratory diseases as a major disease in FP7.

\section{COMMITTED SUPPORT OF THE EP FOR CHRONIC RESPIRATORY DISEASES}

The ERS received cross-political support from the EP for an amendment to include respiratory diseases in FP7. In the first round of negotiations the EP introduced improvements to the FP7 text, proposing the inclusion of respiratory diseases as a major disease in the FP7 Health theme.

The ERS continued campaigning until the very end. The compromise finally reached now explicitly includes "respiratory diseases including those induced by allergies" under "other chronic diseases" of the FP7 Health research theme and "Translational research in major diseases". This has been a significant achievement and will allow application for specific research proposals targeted at respiratory diseases to be submitted, which in the long term will benefit patients who suffer from these disorders.

\section{STRUCTURE AND BUDGET OF FP7}

The main portion of the funding, $€ 32$ billion, will be allocated to cooperative trans-national projects (table 1). The main project types will be: 1) collaborative projects i.e. large and smaller research projects; 2) networks of excellence, which are large research networks; and 3) coordination and support actions, which include smaller research networks and other initiatives [7].

\section{WHAT'S IN FP7 FOR RESPIRATORY RESEARCH?}

Many of the research themes may look familiar to respiratory scientists. This is because they are carried over from the previous FP6. Of the 10 research themes one is entirely dedicated to health, receiving a total of $€ 6$ billion in funding, distributed evenly over the next 7 yrs. Some examples of upcoming calls within the Health theme and of potential

\section{TABLE 1 The indicative breakdown among programmes (€ million)}

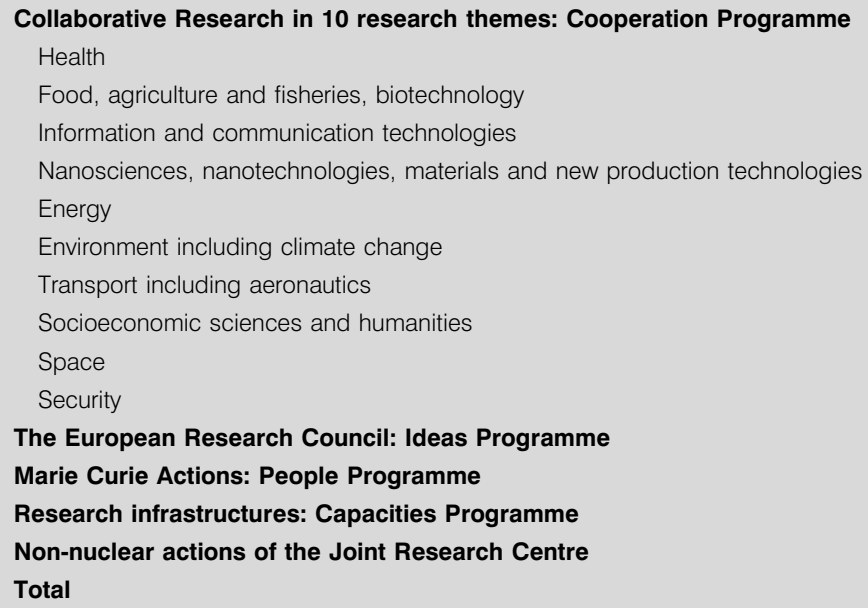


interest are as follows [7]. 1) Poverty-related disease will include calls on tuberculosis. 2) Infectious diseases will include specific calls relating to anti-microbial resistance and emerging epidemics, e.g. highly pathogenic influenza viruses. 3) Major diseases will include specific calls in the field of cancer. Rare diseases are covered here with a call on the natural course and pathophysiology on rare diseases affecting the respiratory system. Within other chronic diseases there will be a call on innovative concepts in chronic obstructive pulmonary disease pathogenesis in 2007, as well as a topic on the early processes in the pathogenesis of chronic inflammatory diseases including asthma.

In addition to the Health research theme, research under the Information and Communication Technologies (ICT) theme will encompass the topic "ICT for health". The Environment theme will also have calls for research under an activity labelled "Environment and Health". The NMP (Nanosciences, Materials and New Production Technologies) theme will have calls in the field of nanomedicine covering topics such as nanotechnologybased systems for in-vivo/in-vitro diagnosis and therapy.

The vehicle for supporting fundamental research across all scientific disciplines will be realised by the new European Research Council. Two types of grants, starting grants and advanced grants, will be awarded to projects of groundbreaking nature, evaluated on the sole criterion of excellence. Fellowships aimed at training researchers will also run under a set of Marie Curie Actions under the "People" programme.

\section{THE INNOVATIVE MEDICINES INITIATIVE}

The Innovative Medicines Initiative (IMI) intends to support a faster discovery and development of better medicines for patients while also strengthening the competitiveness of the biopharmaceutical sector in Europe [8]. The anticipated launch of the IMI led by the European Federation of the Pharmaceutical Industries and Associations, the research-based pharmaceutical industry in Europe, represents a unique collaboration of unparalleled scale, requiring an investment of about $€ 3$ billion over 7 yrs.

The IMI will be launched in mid 2007 as a new non-profit international organisation with a legal mandate to award research grants to European public-private collaborations. A Strategic Research Agenda finalised in September 2006 suggests some clear and practical paths to accelerate the drug development process by involving all stakeholders such as clinicians, the biopharmaceutical industry, patients, regulators, clinicians, healthcare companies and academia.

\section{CONCLUSION}

Looking back at the recent Seventh Framework Programme campaign of the European Respiratory Society, and the efforts that were launched and mobilised throughout the past $3 \mathrm{yrs}$, some clear messages and thoughts for the future European Respiratory Society advocacy strategy have emerged. These will need to be developed further in the coming year and will hopefully lead to a stronger political commitment at all levels to fight respiratory diseases in the three domains mentioned earlier. Indeed, the inclusion of respiratory diseases in the Seventh Framework Programme has been a major success of the advocacy policy and grateful thanks are extended to all who worked on this project. With its networking and dissemination expertise, the European Respiratory Society is ready to collaborate with academic institutions and research centres willing to participate in upcoming calls for research proposals.

\section{REFERENCES}

1 European Respiratory Society/European Lung Foundation. European Lung White Book. The First Comprehensive Survey on Respiratory Health in Europe. Loddenkemper R, Gibson GJ, Sibille Y, eds. Sheffield, ERSJ, 2003.

2 World Health Organization. Preventing chronic diseases: a vital investment. 2005. www.who.int/chp/chronic_ disease_report/contents/en/index.html. Date last accessed: December 2006.

3 Strong K, Mathers C, Leeder S, Beaglehole R. Preventing chronic diseases: how many lives can we save? Lancet 2005; 366: 1578-1582.

4 Horton R. The neglected epidemic of chronic disease. Lancet 2005; 366: 1514.

5 Bousquet J, Dahl R, Khaltaev N. Global Alliance against Chronic Respiratory Disease. Eur Respir J 2007; 29: 233-239.

6 World Health Organization. Global Alliance against Chronic Respiratory Diseases (GARD). www.who.int/respiratory/ gard/en/. Date last accessed: December 2006.

7 CORDIS. Towards FP7 your gateway to the preparation of the Seventh Framework Programme. http://cordis. europa.eu/fp7/. Date last accessed: December 2006. Date last updated: December 2006.

8 Life sciences, genomics and biotechnology for health. Innovative Medicines Initiative. http://ec.europa.eu/ research/fp6/index_en.cfm? $\mathrm{p}=1$ _innomed. Date last accessed: December 2006. 